\title{
Radiology in diffuse parenchymal lung disease and lung nodules
}

\author{
Nicola Sverzellati ${ }^{1}$ and Sujal Desai ${ }^{2}$ \\ Affiliations: ${ }^{1}$ Radiology, Dept of Medicine and Surgery, University of Parma, Parma, Italy. ${ }^{2}$ London Bridge \\ Hospital, London, UK. \\ Correspondence: Nicola Sverzellati, Scienze Radiologiche, Padiglione Barbieri, Azienda Ospedaliero- \\ Universitaria di Parma, Via Gramsci 14, Parma, 43126, Italy. E-mail: nicolasvedatiscali.it
}

@ERSpublications

A series of articles on radiology begins in the European Respiratory Review http://ow.ly/8dVC30boxcA

Cite this article as: Sverzellati N, Desai S. Radiology in diffuse parenchymal lung disease and lung nodules. Eur Respir Rev 2017; 26: 170049 [https://doi.org/10.1183/16000617.0049-2017].

It is a privilege and honour to introduce a new series entitled "Radiology" that is starting in this issue of the European Respiratory Review (ERR). The series focuses on diagnostic imaging and we are sure it will be of great interest for physicians dealing with both diffuse parenchymal lung disease (DPLD) and lung nodules. Indeed, the management of DPLD and incidentally identified lung nodules on computed tomography (CT) is, to say the least, difficult. Diagnostic uncertainty and variation in choice of treatment or follow-up among pulmonologists, radiologists and pathologists are common sources of clinical discussion. The arena of DPLD and incidental lung nodules is topical and both are the subject of recently published or to-be-published guidelines [1,2].

To those already working in the field of DPLD, it will be abundantly clear that diagnostic uncertainty (based on a review of clinical data, high-resolution computed tomography (HRCT) appearances and/or the pathological findings) is part and parcel of the clinical challenge. The benefits of a multidisciplinary approach to the management of patients with DPLD are well known $[1,3,4]$. This is perhaps most important for the more complex cases and this, needless to say, mandates quality criteria for a multidisciplinary diagnosis. A tantalising insight into the workings of a multidisciplinary team is provided in the current issue of the ERR by WALSH [5], who discusses the more challenging (and, sometimes, perplexing) aspects of the inter-specialty discussion. The author highlights the role of HRCT and the dynamic nature of the diagnostic process incorporating clinical and morphological findings.

Another important aspect of management in DPLD is the issue of follow-up. Accordingly, ELICKER et al. [6] will discuss the role of follow-up HRCT, which is underscored by recent guidelines [1, 7]. Indeed, longitudinal data, including the results of HRCT studies, suggest that disease "behaviour" over time provides useful diagnostic information. This is particularly true of "outlier" cases or in patients with incomplete diagnostic information (for instance, in those subjects in whom surgical lung biopsy is not feasible).

The article by Roвbie et al. [8] will complete the circle by presenting some of the current thinking about HRCT in usual interstitial pneumonia/idiopathic pulmonary fibrosis. If not already in the mainstream, the term quantitative CT is likely to become increasingly familiar, to pulmonologists and radiologists alike, in the next 5-10 years. Data from different sources suggest that the prognostic "signal" from computer-based

Received: April 132017 | Accepted after revision: April 272017

Conflict of interest: Disclosures can be found alongside this article at err.ersjournals.com

Provenance: Commissioned article, peer reviewed.

Copyright CERS 2017. ERR articles are open access and distributed under the terms of the Creative Commons Attribution Non-Commercial Licence 4.0. 
analyses of HRCT images is stronger than that based on the more traditional visual assessment $[9,10]$. This is likely to be of interest to many but especially to those charged with drug development and to clinical trials co-ordinators, for whom accurate stratification of disease extent and morphological characterisation are a sine qua non. Tools for quantitative analysis of imaging studies are now almost routinely provided by the major CT manufacturers and it seems likely that the next decade will see a significant expansion in applications of computer-generated CT analyses in clinical practice.

Also to be included in this series is the forthcoming article by LARICI et al. [11]. Fuelled somewhat by data from lung cancer screening trials (including the National Lung Screening Trial in the USA, as well as European studies), there has been a global increase in the awareness of incidental lung nodules and, more importantly, what to do with them. Guidelines for the follow-up and management of nodules have been published by, among others, the Fleischner Society and the British Thoracic Society [2, 12]. LARICI et al. [11] will tackle the issues that govern lung nodule management. Notably, they will emphasise the features, other than size, which might be of greatest importance when deciding on the optimal follow-up strategy.

It is our hope that readers will find the articles in this series both informative and of specific value to their own practice. We believe that these will not only build on existing knowledge but also familiarise readers with the prospects and challenges in the challenging arena of DPLD and lung nodules.

\section{References}

1 Travis WD, Costabel U, Hansell DM, et al. An official American Thoracic Society/European Respiratory Society statement: update of the international multidisciplinary classification of the idiopathic interstitial pneumonias. Am J Respir Crit Care Med 2013; 188: 733-748.

2 MacMahon H, Naidich DP, Goo JM, et al. Guidelines for management of incidental pulmonary nodules detected on CT images: from the Fleischner Society 2017. Radiology 2017: 161659.

3 Flaherty KR, King TE Jr, Raghu G, et al. Idiopathic interstitial pneumonia: what is the effect of a multidisciplinary approach to diagnosis? Am J Respir Crit Care Med 2004; 170: 904-910.

4 Walsh SL, Wells AU, Desai SR, et al. Multicentre evaluation of multidisciplinary team meeting agreement on diagnosis in diffuse parenchymal lung disease: a case-cohort study. Lancet Respir Med 2016; 4: 557-565.

5 Walsh SLF. Multidisciplinary evaluation of interstitial lung diseases: current insights. Eur Respir Rev 2017; 26 : 170002.

6 Elicker BM, Kallianos KG, Henry TS. The role of high-resolution computed tomography in the follow-up of diffuse lung disease. Eur Respir Rev 2017; in press [https://doi.org/10.1183/16000617.0008-2017].

7 Sverzellati N, Lynch DA, Hansell DM, et al. American Thoracic Society-European Respiratory Society classification of the idiopathic interstitial pneumonias: advances in knowledge since 2002. Radiographics 2015; 35: 1849-1871.

8 Robbie H, Daccord C, Chua F, et al. Evaluating disease severity in idiopathic pulmonary fibrosis. Eur Respir Rev 2017; in press [https://doi.org/10.1183/16000617.0051-2017].

9 Jacob J, Bartholmai BJ, Rajagopalan S, et al. Mortality prediction in idiopathic pulmonary fibrosis: evaluation of computer-based CT analysis with conventional severity measures. Eur Respir J 2017; 49: 1601011.

10 Salisbury ML, Lynch DA, van Beek EJ, et al. Idiopathic pulmonary fibrosis: the association between the adaptive multiple features method and fibrosis outcomes. Am J Respir Crit Care Med 2017; 195: 921-929.

11 Larici AR, Farchione A, Franchi P, et al. Lung nodules: is size really that important? Eur Respir Rev 2017; in press [https://doi.org/10.1183/16000617.0025-2017].

12 Baldwin DR, Callister ME. The British Thoracic Society guidelines on the investigation and management of pulmonary nodules. Thorax 2015; 70: 794-798. 